\title{
THREE-DIMENSIONAL MODELING OF THE ROMANESQUE CHURCH OF SANTA MARIA DE CASTRELOS (VIGO - SPAIN) USING TERRESTRIAL LASER SCANNER
}

\author{
A. Soria-Medina ${ }^{\text {a, }}$, J. Martinez $^{\text {b }}$, P. Arias ${ }^{\text {b }}$, . Armesto $^{\text {b }}$, A. Z. Buffara-Antunes ${ }^{\text {a }}$
}

\author{
${ }^{\text {a } U F P R, ~ G e o m a t i c s ~ D e p a r t m e n t, ~ F e d e r a l ~ U n i v e r s i t y ~ o f ~ P a r a n a, ~ C u r i t i b a, ~ P a r a n a, ~ B r a z i l ~-~(a s m e d i n a, ~ f e l i p e) @ u f p r . b r ~}$ \\ b Natural Resources Department, Mining School, University of Vigo, Spain, (Joaquin.martinez, parias, Julia)@uvigo.es
}

KEY WORDS: Terrestrial laser scanning, Romanesque Church, 3D model, Planes, Sections, CAD

\begin{abstract}
:
This article shows the results obtained in the three dimensional survey of the church of Santa Maria of Castrelos realized through a terrestrial Laser Scanner. The Church of Santa Maria of Castrelos, which was built in the early thirteenth century, is located in Vigo Spain. It is a Romanesque style church with a nave and semicircular apse with three gates decorated with rosettes and typically Romanesque geometrical figures. The survey was conducted by the laboratory of Close Range Photogrammetry of Natural Resources Department, Mining School, at University of Vigo - Spain, jointly with the Geomatics Department, Federal University of Parana Brazil. This work explores the use of laser scanning for the surveying, three-dimensional modeling and documentation of historical monuments but also the generation of quoted plans and cross sections of this Romanesque church in the city of Vigo. The resolution of point clouds used to obtain the models varied according to need. Namely, the point cloud used for three-dimensional model for the general external and internal church was used with an approximate step width of $10 \mathrm{~cm}$, while $5 \mathrm{~cm}$ and $1 \mathrm{~cm}$ step widths were used for details of geometric figures and rosettes. The results of both the three-dimensional model and the plans and sections are in accordance with the specifications and scales of representation usually used in conventional surveys of historic monuments recommended in the specialized literature in the area. The objective of this study is showing the potential of the use of terrestrial laser scanner in the documentation of historical heritage through achieving the 3D model by joining external and internal point clouds and the generation of planes and sections of the church of Santa Maria of Castrelos, Vigo.
\end{abstract}

\section{INTRODUCTION}

\subsection{General Instructions}

Surveying the cultural heritage is very important to document the natural, historical and touristic heritage and connect the past and the future for any nation. There are many methods for the documentation of the cultural heritage, like traditional manual measurement, topographical, Photogrammetric and Laser scanning methods.

In recent years, with the use of laser scanning technology for Photogrammetric applications thousands of points on objects surface are obtained with less effort in terms of time and cost than required for three dimensional measurements based on classic methods.

In this study, the potential of the use of terrestrial laser scanner in the documentation of historical heritage is shown, both for 3D modeling of joint external and internal point clouds as well as for generation of planes and sections of the church of Santa Maria of Castrelos, Vigo.

\section{MATERIAL AND METHOD}

\subsection{Santa Maria de Castrelos Church}

The Church of Santa Maria of Castrelos, which was built in the early thirteenth century, is located in Vigo Spain. It is a Romanesque style church with a nave and semicircular apse with three gates decorated with rosettes and typically
Romanesque geometrical figures. The figure 1 shows the Santa Maria of Castrelos church.

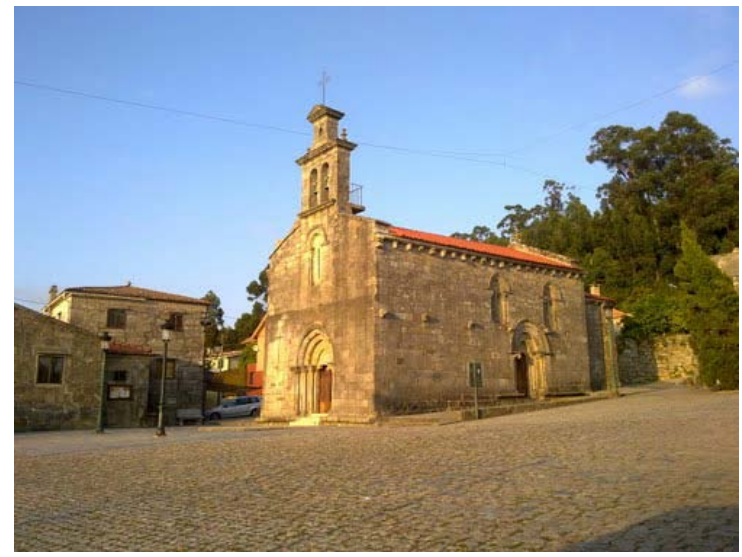

Figure1 Santa Maria of Castrelos Church.

\subsection{Terrestrial Laser Scanner Riegl-390i}

This scanner is based on the time-of-flight (TOF) principle and has a laser source that emits pulses with a wavelength of 1500 $\mathrm{nm}$. This device measures distances in the range of 1.5 to $400 \mathrm{~m}$ with an accuracy rating of $6 \mathrm{~mm}$ at a distance of $50 \mathrm{~m}$ in normal conditions of illumination and reflectivity. The Riegl 390i is an hybrid laser: this means that the scanning is unrestricted in the

\footnotetext{
* Corresponding author. asmedina@ufpr.br.
} 
horizontal movement with a 360 deg field of view (HFOV) and has a restricted vertical field of view (VFOV) of 80deg. Some technical data from Riegl specifications are shown in table 1. The minimum and maximum angular resolution is $0.2^{\circ}$ and $0.002^{\circ}$, respectively. The maximum measuring point rate is 11,000 points per second. The beam divergence is $0.3 \mathrm{mrad}$, equivalent to $30 \mathrm{~mm}$ per each $100 \mathrm{~m}$ range. The intensity of the signal received by the sensor system is written in 8 bits [0 255].

Table 1: Some technical especifications of Riegl LMS-390i are sumarized.

\begin{tabular}{|l|l|}
\hline Metrology method & Time of flight \\
\hline Max angular resolution & 0.002 (deg) \\
\hline Measurement range & $1.5 \mathrm{~m}$ - 400m \\
\hline Accuracy & $6 \mathrm{~mm}$ (one sigma @ 50m) \\
\hline Repeatability & $4 \mathrm{~mm}$ (one sigma @ 50m) \\
\hline $\begin{array}{l}\text { Laser beam divergence } \\
\text { (full angle, } 1 / e^{2} \text { value) }\end{array}$ & typ. 0.3 mrad \\
\hline $\begin{array}{l}\text { Inclination } \\
\text { precision }\end{array}$ & 0.05 (deg) \\
\hline \multicolumn{1}{|c|}{ sensors }
\end{tabular}

\section{RESULTS}

Both inner and the outer surface of Santa Maria de Castrelos were scanned from different points of view. All measurements were matched in Riscan Pro software. Figure 2 shows the different positions of scanner stations.

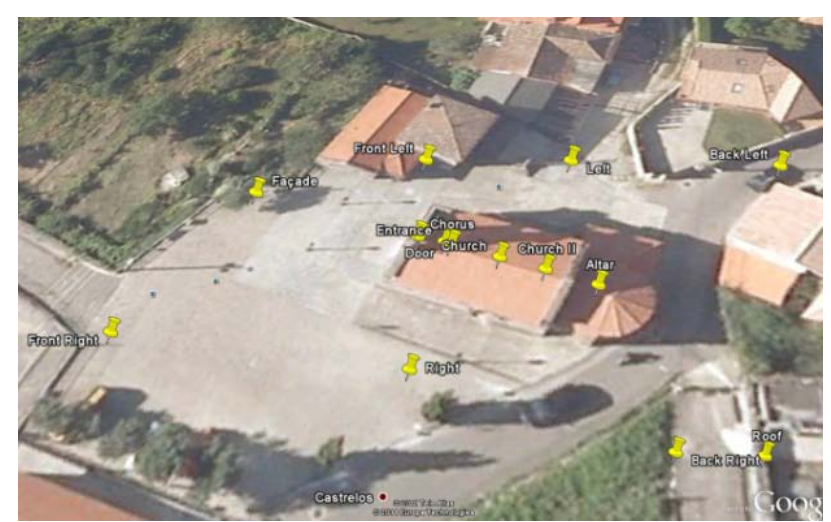

Figure 2 Different scan positions

For the registration of the different point clouds, a Multi Station Adjustment (MSA) procedure is used. MSA is based in the Iterative Closest Point (ICP) algorithm and takes into account the available information about each scanposition, such as tiepoints (targets), tieobjects (planes, points...) defined by the user and polydata objects. These polydata objects are a reduced version of the original point clouds: the ICP algorithm could be very slow when using dense point clouds; to speed up the process, the number of points is reduced by representing them by planes. Once the registration is performed, a registration of the different scanpositions is obtained with a standard deviation of $4.9 \mathrm{~mm}$. Figure 3 shows the graphic of the standard deviations.

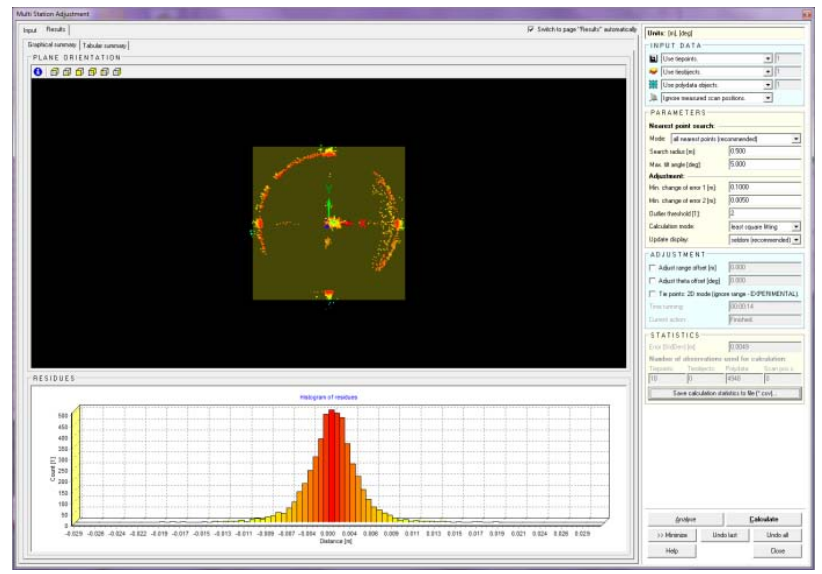

Figure3. Standard deviation of the different scan positions

The three dimensional models obtained with the inner and outer scanning are shown in figure 4.

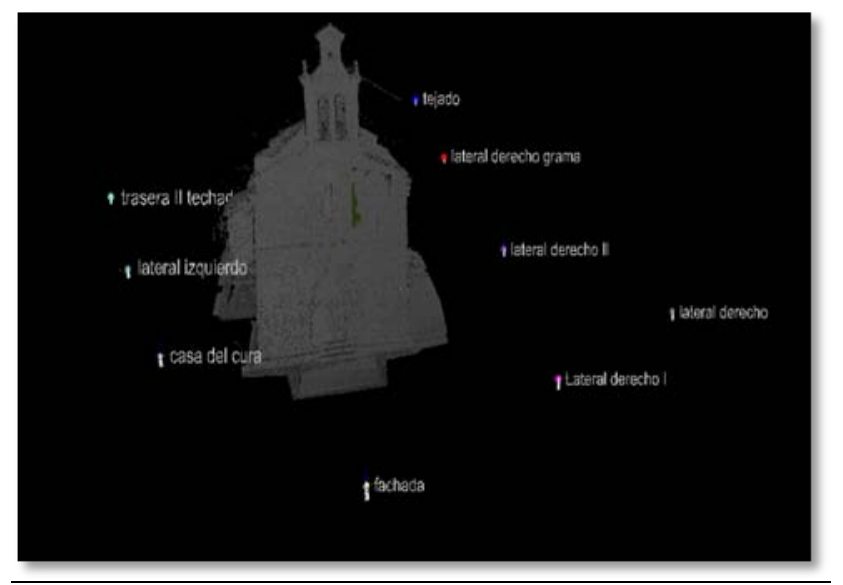

Figure 4. The dimensional model

A number of cross sections were performed in the three dimensional model and exported in dxf format (Drawing Exchange Format) to be used in a CAD system (Computer Aided Design). Next figures show the results of the cross sections made on the three dimensional model. Figure 5 shows the floor plan and figure 6 shows this cross section in a CAD system with dimensions quoted. 


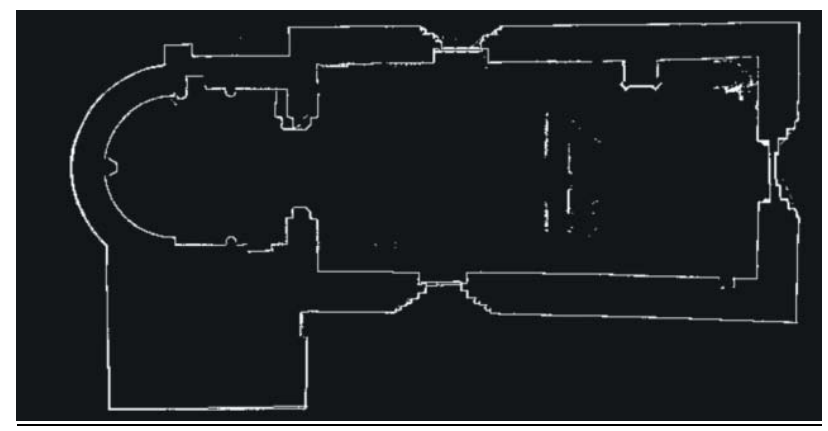

Figure 5. Section of floor plan

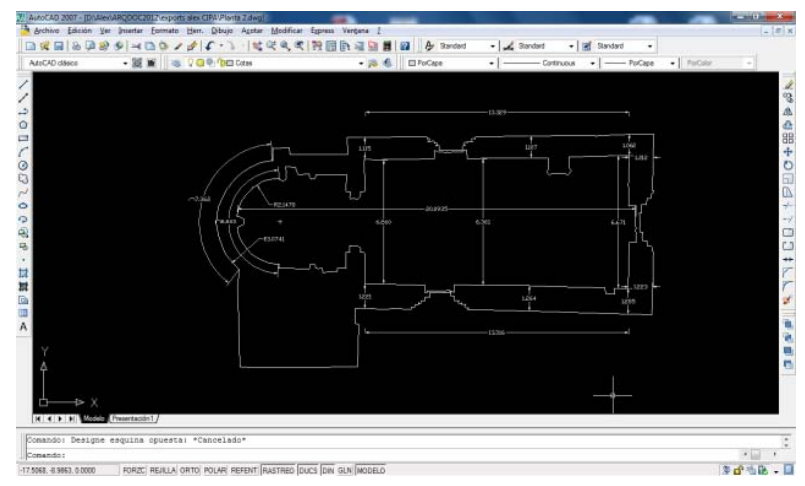

Figure 6. Section of floor plan in a CAD system

Moreover, figure 7 and figure 8 show another cross section in a side view (E-W) as exported by Laser Scanning software and CAD quotation, respectively

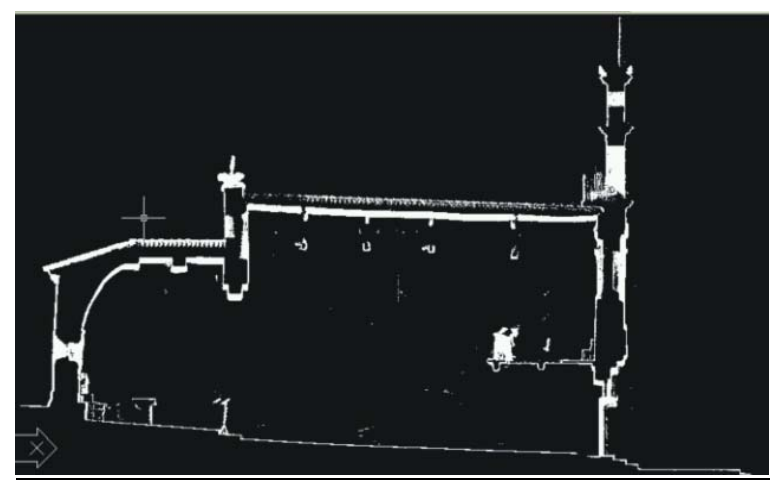

Figure 7. Cross section side view E - W

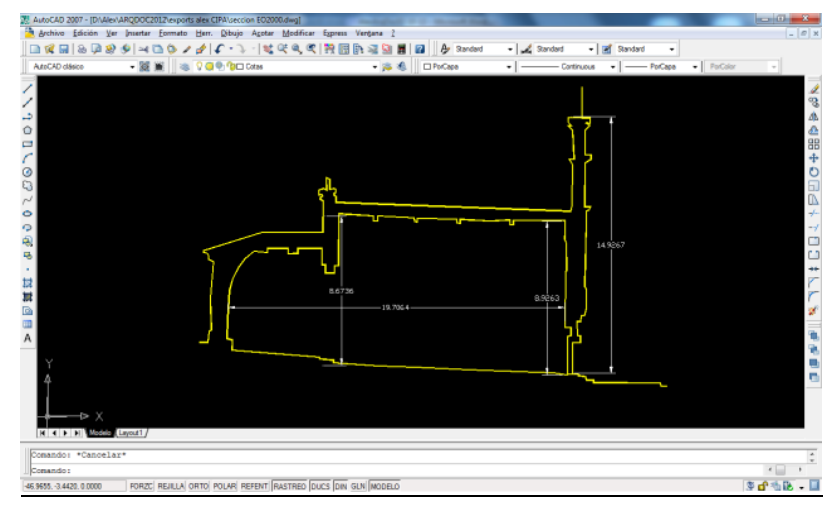

Figure 8. Cross section side view $\mathrm{E}-\mathrm{W}$ in a CAD system.
Another views obtained on the North - South direction are shown in Figures 9 and 10. Figure 9 refers to the point cloud and figure 10 is the results of processing and quotation in Cad system.

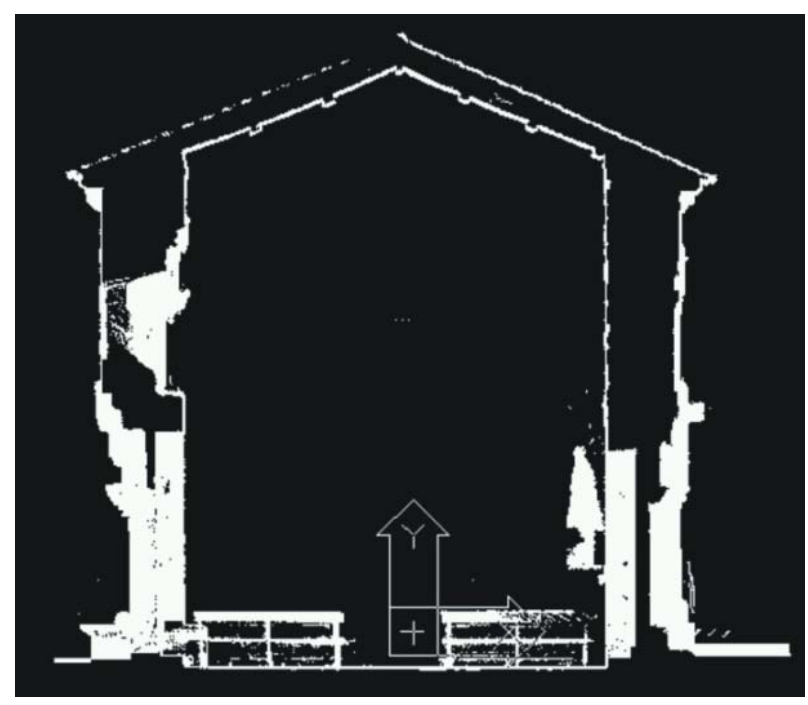

Figure 9. Cross section side view N - S.

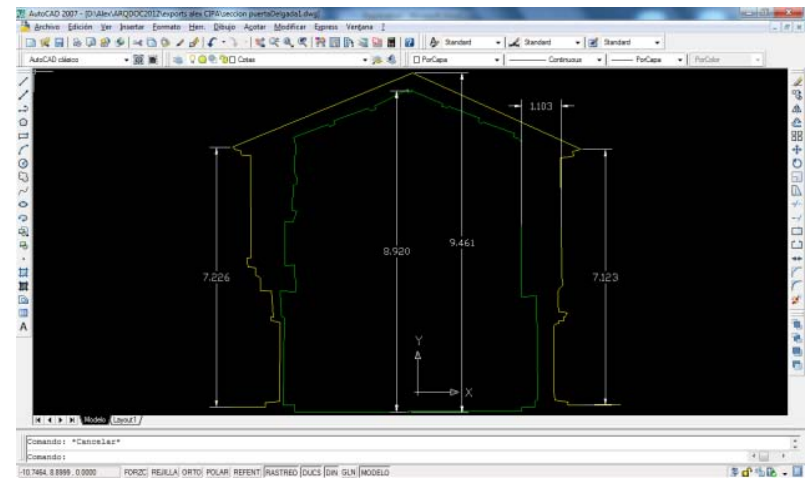

Figure 10. Cross section side view N - S in CAD system.

\section{CONCLUSION}

Cultural heritage may be damaged by many factors. Therefore, heritage inventory and documentation has become essential for information and heritage protection. Restoration in case of damage may be improved through documentation by information systems. This study shows that laser scanning techniques can be applied to obtain a three dimensional model (3D) and to extract cross section of cultural heritage. Laser scanning techniques result in complete and accurate geometric models that are obtained with less effort in terms of time than measurement technique based on the classic methods. As a result of this work, the church of Santa Maria of Castrelos, Vigo was modeled and digitally archived.

\section{ACKNOWLEDGMENTS}

The authors want to thank CAPES Foundation Ministry of Education of Brazil (Process code 0064-10-6), the Ministry of Science and Innovation of Spain (Project code BIA2009-08012) and Regional Ministry of Economy and Industry-Xunta de Galicia (Isabel Barreto EXP114) for the financial support. 


\section{References:}

DOMINIC, S. 2007, A Recent Case of 3D Survey for Heritage Conservation in Civil Engineering and Development Department - The Old Star Ferry Pier, Hong Kong Institute of Surveyors "Annual Conference 2007 Surveyors in Heritage Preserving and Adding Value”, 13 October 2007, JW Marriott Hong Kong.

GUIDI, G., REMONDINO, F., RUSSO, M., MENNA, F., RIZZI, A., ERCOLI, S. A multi-resolution methodology for the 3d modeling of large and complex archeological areas. International Archives of Photogrammetry, Remote Sensing and Spatial Information Sciences. 2008.

PU, S; VOSSELMAN, G; Automatic extraction of building features from terrestrial laser scanning. International Archives of Photogrammetry, Remote Sensing and Spatial Information Sciences, Vol. XXXVI, part. 5. Dresden, Germany, 2006.

RABBINI, T; VAN DEN H. AND VOSSELMAN, G. Segmentation of point cloud using smoothness constrain. International archives of photogrammetry and remote sensing, Remote sensing and spatial Information Sciences, Vol. XXXVI, part. 5. Dresden, Germany, 2006. 